\title{
Preventing Colonization by Lung Isolation: Primum Non Nocere
}

Tracheal intubation is among the most dangerous of interventions in the patient who is critically ill. The procedure of laryngoscopy itself is potentially hazardous, but this can normally be managed in a controlled manner. It is the state of being intubated over a number of days or weeks that carries particular risk and can only be in part ameliorated by care bundles to try to reduce the colonization and aspiration of secretions. Approximately 20\% of patients who are intubated acquire a ventilator-associated pneumonia (VAP), and, of these patients, the attributable mortality is as high as $13 \% .{ }^{1}$ Many more acquire colonization of the trachea and lung tissue, a prerequisite to VAP. VAP normally begins with sequential upper aerodigestive, then tracheal and lung colonization, and, if the pathogenic bacterial load overwhelms lung defenses, then invasive tissue infection ensues. ${ }^{2}$

The phenomena and mechanism of silent aspiration past an inflated high-volume low-pressure cuff has been understood for more than 40 years. ${ }^{3}$ Continual or episodic leakage of bacterial-laden secretions past an inflated cuff during intubation is the fundamental step of transfer, ${ }^{4}$ and, in recognition of this, VAP is suggested to be more correctly called endotracheal tube-associated pneumonia. ${ }^{5}$ It is vital for industry to innovate to solve this endotracheal tube malfunction, and, yet, it is equally important for health services, institutions, and clinicians to be open to adoption when suitable technologies emerge.

Adoption of new innovations is said to average 17 years. ${ }^{6}$ Subtle perverse financial incentives and "gaming" may come into play at a local institutional level, ${ }^{7}$ and cost-effective solutions with a high upfront cost may require national tariffs to enable faster adoption across healthcare systems (https://www. england.nhs.uk/2016/06/treatment-innovations. Accessed August 1, 2019). We should be prepared to invest for prevention. Wyncoll and Camporota ${ }^{8}$ estimated con-

Dr Young discloses relationships with the NHS, Medovate, Amdel Medical, Qualitech Healthcare, and Venner Medical. Dr Young is the inventor of the PneuX Pneumonia Prevention System and a number of other airway and patient safety devices.

Correspondence: Peter J Young MD, Department of Critical Care, Gayton Road, Kings Lynn, PE30 4ET, United Kingdom. E-mail: Peteryoung101@gmail.com.

DOI: $10.4187 /$ respcare .07340 siderable cost savings for most institutions, even if spending hundreds or thousands of dollars for preventive technologies for VAP.

SeE the Original Study on Page 1031

Current VAP prevention programs aim to minimize intubation time, to reduce the volume and bacterial load of subglottic fluid (oral hygiene and infection control) and to reduce transcuff aspiration (semi-recumbency, cuff-pressure maintenance, subglottic drainage). The ideal aim is to isolate the lungs from ongoing contamination throughout mechanical ventilation. To achieve this reliably, and assuming robust infection control of the inner ventilation tubing, one must address 3 mechanisms of aspiration past the cuff: (1) through longitudinal channels within the inflated cuff, (2) with rotational or longitudinal cuff movement that causes folding, and (3) with sustained low cuff pressure or intermittent loss of cuff pressure. ${ }^{9}$ Caregivers reliably and continuously applying bundles of partially effective interventions to prevent the risk factors for VAP is laudable but likely to be only partially effective. Developing a reliable and convenient tool as an engineered solution to solve the problem is likely to be a more robust and complete solution.

In this issue of Respiratory Care, Rezoagli et al ${ }^{10}$ present a prototype "leak-proof" double-layer guayule latex endotracheal cuff tested in an enterally fed pig model of extended ventilation (no. $=5$ ). The guayule cuff is snug to the tube and designed to eliminate folds at the cuff-trachea interface. They tested macroscopic leakage by using methylene blue dye and bacterial colonization of the lungs at $72 \mathrm{~h}$. No dye was judged to have leaked in the leak-proof cuff group, and the proportion of colonized lung lobes was significantly reduced, from $92 \%$ to $27 \%$, with an associated reduction in hypoxemia. Most impressively, the median bacterial load reduced very substantially, the difference nicely displayed on a Karnaugh color map.

There are a number of criticisms regarding this study that the authors have, in part, addressed, including the historical controls and associated potential selection bias, different pathogen profiles to those in a human ICU, and the small sample size of the prospective study group. However, the absence of the use of a ventilator care bundle, the 


\section{EDITORIALS}

greater use of enteral feeding, the complete omission of oral hygiene, the unfavorable position of the trachea and the manipulation and movement of the tube during bronchoscopy would have provided a greater challenge to the leak-proof cuff.

This makes the result all the more remarkable. A clinically demonstrable large oxygenation benefit alongside substantial reductions in colonization were achieved by changing a single variable, the provision of an effective cuff. These data, in combination with the mechanistic understanding above, indicates an important target for such an engineered solution to the problem. Although the group previously showed ${ }^{11}$ that the double-layer guayule cuff prevents leakage in bench models, it must also work with rotational and longitudinal movement in a non-uniform human trachea in life and must remain inflated at all times, without even a momentary failure. It is possible that the leak-proof cuff did not maintain its full inflation throughout the 72-h period, despite 6-h checks. Movements and natural deflation over time occur between checks, and, also, when using a manual cuff manometer, it is possible, or even probable, to temporarily deflate the cuff, depending on technique and equipment dead space and ergonomics. ${ }^{12}$ Even if this was well controlled within the present study, continuous inflation would be needed to secure the seal if translated to multiple users in clinical practice. This suggests that even more remarkable improvements in bacterial soiling of the lung shown in the present study are possible.

Notably, the wealth of subglottic drainage clinical studies showed only $50 \%$ reductions in infections. Subglottic drainage reduces lung soiling but does not provide lung isolation because this is by no means fully effective at clearing secretions or reducing objective outcomes $^{13}$ and a "leaky" cuff remains. Constant pressure control with high-volume low-pressure cuffs again has only a partial effect. ${ }^{14}$ Human studies that combine a leak-free cuff in combination with subglottic drainage and irrigation, and continuous cuff pressure control have shown VAP reduction ${ }^{15}$ and, more remarkably, tracheal colonization prevention. ${ }^{16}$ It is a shame that the microbiology of the 6-h samples obtained with endotracheal suctioning were not reported in the present study. One would expect that these would have been less microbe burdened (if at all) than the control group, and this is a parameter that a clinician has convenient access to in human practice.

VAP is the leading cause of nosocomial mortality in the ICU and, therefore, prolonged tracheal intubation is possibly the most dangerous thing that we do to patients under our watch; so it behooves us to develop and embrace technologies to prevent this. We should consider using tracheal and lung colonization as a quality indicator as measured by simple tracheal aspirates. Few of us (and few of our patients) would argue that the ingress of pathogenic bacterial to the lower respiratory tract is desirable, it is just so common place that it has somehow become acceptable and deemed by many unavoidable. VAP must be diagnosed (albeit with difficulty and imprecision) to decide on antibiotic choice and when to withhold. However, in terms of prevention and quality improvement, we should aim to eliminate tracheal colonization because this offers a higher standard and is more objective. Without preceding tracheal and lung colonization, VAP is unlikely. The high-volume lowpressure cuff was developed in the late 1960s during the expansion of modern intensive care as a quick fix to the tracheal trauma of the widespread use of red-rubber high-pressure cuffs for more extended periods. It has been long known that there is a basic design flaw to the high-volume low-pressure cuff and engineered solutions should be developed and adopted.

Peter J Young

Department of Critical Care Queen Elizabeth Hospital Kings Lynn United Kingdom

\section{REFERENCES}

1. Melsen WG, Rovers MM, Groenwold RH, Bergmans DC, Camus C, Bauer $\mathrm{T}$ et al. Attributable mortality of ventilator-associated pneumonia: a meta-analysis of individual patient data from randomised prevention studies. Lancet Infect Dis 2013;13(8):665-671.

2. Feldman C, Kassel M, Cantrell J, Kaka S, Morar R, Goolam Mahomed A, Philips J. The presence and sequence of endotracheal tube colonization in patients undergoing mechanical ventilation. Eur Respir J 1999;13(3):546-551.

3. Pavlin EG, VanNimwegan D, Hornbein TF. Failure of a high-compliance low-pressure cuff to prevent aspiration. Anesthesiology 1975; 42(2):216-219.

4. Craven D. Prevention of hospital-acquired pneumonia: measuring effect in ounces, pounds, and tons. Ann Intern Med 1995;122(3):229-231.

5. Pneumatikos IA, Dragoumanis CK, Bouros DE. Ventilator-associated pneumonia or endotracheal tube-associated pneumonia? An approach to the pathogenesis and preventive strategies emphasizing the importance of endotracheal tube. Anesthesiology 2009;110(3):673-680.

6. Balas EA, Boren SA. Managing clinical knowledge for health care improvement. Yearb Med Inform 2000;(1):65-70.

7. Klompas M, Berra L. Should ventilator-associated events become a quality indicator for ICUs? Respir Care 2016;61(6):723-736.

8. Wyncoll D, Camporota L. Number needed to treat and cost-effectiveness in the prevention of ventilator-associated pneumonia. Crit Care 2012;16(3):430.

9. Young P, Doyle A. Preventing ventilator-associated pneumonia - the role of the endotracheal tube. Curr Respir Med Rev 2012;8:170-183.

10. Rezoagli E, Cressoni M, Bellani G, Grasselli G, Pesenti AM, Kolobow $\mathrm{T}$, et al. Prevention of lung bacterial colonization with a leak-proof endotracheal tube cuff: an experimental animal study. Respir Care 2019;64(9):1031-1041.

11. Zanella A, Cressoni M, Epp M, Stylianou M, Kolobow T. A doublelayer tracheal tube cuff designed to prevent leakage: a bench-top study. Intensive Care Med 2008;34(6):1145-1149. 


\section{EDITORIALS}

12. Patel V, Hodges EJ, Mariyaselvam MZ, Peutherer C, Young PJ. Unintentional endotracheal tube cuff deflation during routine checks: a simulation study. Nurs Crit Care 2019;24(2):83-88.

13. Caroff DA, Li L, Muscedere J, Klompas M. Subglottic secretion drainage and objective outcomes: a systematic review and metaanalysis. Crit Care Med 2016;44(4):830-840.

14. Lorente L, Lecuona M, Jiménez A, Lorenzo L, Roca I, Cabrera J, et al. Continuous endotracheal tube cuff pressure control system protects against ventilator-associated pneumonia. Crit Care 2014;18(2):R77.
15. Gopal S, Luckraz H, Giri R, Nevill A, Muhammed I, Reid M, et al. Significant reduction in ventilator-associated pneumonia with the Venner-PneuX System in high-risk patients undergoing cardiac surgery: the Low Ventilator-Associated-Pneumonia study. Eur J Cardiothorac Surg 2015;47(3):e92-e96.

16. Doyle A, Fletcher A, Carter J, Blunt M, Young P. The incidence of ventilator-associated pneumonia using the PneuX System with or without elective endotracheal tube exchange: a pilot study. BMC Res Notes 2011;4:92. 